\title{
Can thymic epithelial cells be infected by human T-lymphotropic virus type 1 ?
}

\author{
Klaysa Moreira-Ramos ${ }^{1,2,3}$, Flávia Madeira Monteiro de Castro', \\ Leandra Linhares-Lacerda ${ }^{1}$, Wilson Savino ${ }^{1 /+}$
}

\author{
'Laboratório de Pesquisas sobre o Timo, Instituto Oswaldo Cruz-Fiocruz, Av. Brasil 4365, 21040-360 Rio de Janeiro, RJ, Brasil \\ ${ }^{2}$ Programa de Pós-Graduação em Oncologia, Instituto Nacional do Câncer, Rio de Janeiro, RJ, Brasil \\ ${ }^{3}$ Universidade Estadual de Ciências da Saúde de Alagoas, Maceió, AL, Brasil
}

The human T-lymphotropic virus type-1 (HTLV-1) is the cause of adult T cell leukaemias/lymphoma. Because thymic epithelial cells (TEC) express recently defined receptors for the virus, it seemed conceivable that these cells might be a target for HTLV-1 infection. We developed an in vitro co-culture system comprising HTLV-1+-infected T cells and human TECs. Infected T cells did adhere to TECs and, after $24 \mathrm{~h}$, the viral proteins gp 46 and p19 were observed in TECs. After incubating TECs with culture supernatants from $H T L V-1^{+}$-infected T cells, we detected gp 46 on TEC membranes and the HTLV-1 tax gene integrated in the TEC genome. In conclusion, the human thymic epithelium can be infected in vitro by HTLV-1, not only via cell-cell contact, but also via exposure to virus-containing medium.

Key words: thymic epithelial cells - HTLV-1 infection - adult T cell leukaemia/lymphoma - cell adhesion

The human T-lymphotropic virus type 1 (HTLV-1) infects approximately 20 million people around the world (Proietti et al. 2005), including people in Brazil. HTLV-1 infection causes various inflammatory disturbances and two different pathologies are observed: HTLV-1-associated myelopathy/tropical spastic paraparesis (HAM/ TSP), which is a neuroinflammatory disease that involves the peripheral nerves of the spinal cord (Osame et al. 1986), and adult T cell leukaemia/lymphoma (ATL), which is characterised by lymphoproliferation of mature $\mathrm{T}$ lymphocytes, particularly $\mathrm{CD} 4{ }^{+} \mathrm{CD} 25^{+}$activated $\mathrm{T}$ cells (Uchiyama et al. 1977).

Although CD4 T lymphocytes are the main targets for HTLV-1, there is evidence that the virus can infect CD8 T lymphocytes (Nagai et al. 2001), thymocytes (MaguerSatta et al. 1995), CD34 ${ }^{+}$progenitor cells (Feuer et al. 1996), endothelial cells (Setoyama et al. 1998), astrocytes (Mor-Vaknin et al. 1998) and dendritic cells (Jones et al. 2008). Recent studies have indicated that some receptors are required for efficient HTLV cell entrance, including glucose transporter-1 (Glut-1) (Manel et al. 2003), heparan sulfate proteoglycans (Jones et al. 2005) and neuropilin-1 (NP-1) (Ghez et al. 2006). These molecules can be found in the thymus (Murdoch et al. 1994, Swainson et al. 2005, Lepelletier et al. 2007), the primary lymphoid organ in which bone marrow-derived cell precursors undergo $\mathrm{T}$ lymphocyte differentiation. In particular, thymic

Financial support: $\mathrm{CNPq} / \mathrm{INCT}$ of Cancer Control, $\mathrm{CNPq} /$ Universal, FIOCRUZ, FAPERJ, AFM

+Corresponding author: savino@ioc.fiocruz.br

Received 25 April 2011

Accepted 22 July 2011 epithelial cells (TECs), the major component of the thymic microenvironment, express large amounts of NP-1 (Lepelletier et al. 2007). Thus, it seemed conceivable that TECs might be a target for HTLV-1 infection.

We approached this issue by applying an in vitro coculture system comprising an $\mathrm{HTLV}-\mathrm{1}^{+}$infected T cell line, C91PL (Popovic et al. 1983); a control uninfected T cell line, CEM (Foley et al. 1965), and a foetal TEC line (Fernandez et al. 1994), which is able to adhere to developing thymocytes (Ribeiro-Carvalho et al. 2002). Cells were grown in Roswell Park Memorial Institute1640 medium supplemented with $10 \%$ foetal calf serum, $2 \mathrm{mM}$ glutamine, $100 \mathrm{U} / \mathrm{mL}$ penicillin and $100 \mathrm{U} / \mathrm{mL}$ streptomycin (Gibco, Scotland, UK) in a $\mathrm{CO}_{2}$ atmosphere at a temperature of $37^{\circ} \mathrm{C}$. Culture flasks containing $2 \mathrm{x}$ $10^{4}$ TECs were washed $24 \mathrm{~h}$ after plating and $2 \times 10^{5}$ cells from CEM or C91PL T cell cultures were added to the flasks and left to adhere for $2 \mathrm{~h}$. Supernatants containing floating lymphocytes were discarded and the contents of each flask (TECs + adhered lymphocytes) were fixed in absolute ethanol, stained with Giemsa and counted to determine the adhesion index (AI), as previously described (Ribeiro-Carvalho et al. 2002):

$$
\text { AI }=\frac{\begin{array}{c}
\text { TECs with } \\
\text { thymocytes } \\
\text { adhered }
\end{array}}{\begin{array}{c}
\text { Total number } \\
\text { of TECs }
\end{array}} \times \frac{\begin{array}{c}
\text { Thymocytes } \\
\text { adhered } \\
\text { on TECs }
\end{array}}{\begin{array}{c}
\text { Total number } \\
\text { of TECs }
\end{array}} \times 100
$$

In other experiments, TECs were detached from the culture flasks using $10 \mathrm{mM}$ ethylenediamine tetraacetic acid and the lymphocytes were harvested, centrifuged and submitted to cytofluorometry. For cytofluorometry analysis we used appropriate dilutions of monoclonal antibodies with the following specificities: NP-1, CCR4 (Pharmingen/Becton-Dickinson, San Diego, USA), 
Glut-1 (R\&D Systems, Minneapolis, USA) and HTLV-1 gp46 (Abcam, Cambridge, USA). Isotype/fluorochromematched unrelated immunoglobulins (Becton Dickinson) were used as negative controls. Immunostaining was performed as follows: cells were incubated with phosphate buffered saline (PBS)/bovine serum albumin $0.5 \% /$ sodium azide $0.05 \%$ for $15 \mathrm{~min}$, exposed to the fluorochrome-labelled antibodies for $20 \mathrm{~min}$, washed in PBS and fixed in $1 \%$ formaldehyde (Ribeiro-Carvalho et al. 2002). Image acquisition and analysis were performed using a FACSCalibur ${ }^{\circledR}$ device (Becton Dickinson) equipped with CellQuest software.

To determine whether viral proteins could be detected in TECs, in some experiments, TECs and C91PL cells were co-cultured for $24 \mathrm{~h}$ and then submitted to double-label immunohistochemistry, as described previously (Lepelletier et al. 2007). For this experiment, we used polyclonal pan-cytokeratin rabbit serum (Dako Co, Carpinteria, USA), anti-HTLV-1 gp46 and anti-HTLV-1 p19 (Abcam) monoclonal antibodies, as well as the secondary antibodies Alexa-488-labelled goat anti-mouse and Alexa-546-coupled goat anti-rabbit Ig (Amersham Biosciences, Buckinghamshire, UK). TECs were cultured for $24 \mathrm{~h}$ in Lab-Tek chambers and were sequentially subjected to a given primary monoclonal antibody and the corresponding fluorochrome-labelled anti-mouse second antibody, followed by incubation with the anti-cytokeratin serum, the binding of which was revealed with specific fluorochrome-coupled secondary antibodies. The slides were then analysed by fluorescence microscopy.

Other experiments were designed to determine whether culture supernatants derived from $\mathrm{HTLV}-1^{+} \mathrm{T}$ cells could convey viral elements to cultured TECs. For these experiments, lymphocytes $\left(2 \times 10^{6} / \mathrm{mL}\right)$ were cultured for $72 \mathrm{~h}$ in Falcon tubes and centrifuged, and the supernatants were filtered through $0.22 \mu \mathrm{M}$ pore size membranes, which retain cells but allow the passage of virus particles. We then plated $5 \times 10^{5}$ TECs in culture flasks. Twenty-four hours later, these cells were incubated for 90 min with supernatants derived from infected or uninfected lymphocytes. Cells were then harvested and labelled with antibodies against the viral proteins gp46 and p19. Alternatively, their DNA was extracted for polymerase chain reaction (PCR) analysis. For PCR, genomic DNA from TECs exposed to lymphocyte-derived culture supernatants was extracted using the Wizard SV Genomic DNA Purification System kit from Promega Co (Madison, USA), according to the manufacturer's instructions. The primers and the procedures used for PCR were derived from prior research (Lee et al. 2004).

For the various experiments summarised above, quantitative data were expressed as the mean \pm standard error and the results were statistically analysed using Student $t$ test. Differences were considered statistically significant when the $\mathrm{p}$ values were $<0.05$.

In the first set of experiments, we showed that after $2 \mathrm{~h}$ in co-cultures, infected T cells were able to adhere to TECs, exhibiting an AI that was significantly higher than that obtained with the uninfected T cells (Fig. 1). We thus tested whether, in heterocellular cell-cell adhe- sion conditions, we could detect viral proteins in TECs. We co-cultured the cells for $24 \mathrm{~h}$ and then the TECs were stained with anti-cytokeratin and anti-gp46 antibodies. As seen in Fig. 2A, viral gp46 and cytokeratin were co-localised in TEC cultures, indicating that these cells might have HTLV-1 on their surface or in the cytoplasm. This result was confirmed using double-label immunofluorescence for the detection of cytokeratins and the viral matrix protein p19 (Fig. 2B).

We then tested the hypothesis that TECs can be infected by free HTLV-1 virions using the supernatant of infected T cells. Epithelial cells were cultured for $90 \mathrm{~min}$ with supernatant harvested from infected $\mathrm{T}$ cells cultured for $72 \mathrm{~h}$. Cells were then washed, immunostained with the anti-gp46 antibody to detect this viral protein on their surface and analysed by cytofluorometry. As shown in Fig. 2C, only TECs incubated with supernatants from HTLV-1-infected lymphocytes were labelled to visualise viral gp46.

Finally, we used reverse transcription-PCR to screen for the presence of the Tax gene in the genome of TECs treated with HTLV-1 infected cells. These experiments revealed that HTLV-1 was able to penetrate into TECs and integrate its proviral DNA (Fig. 2D).
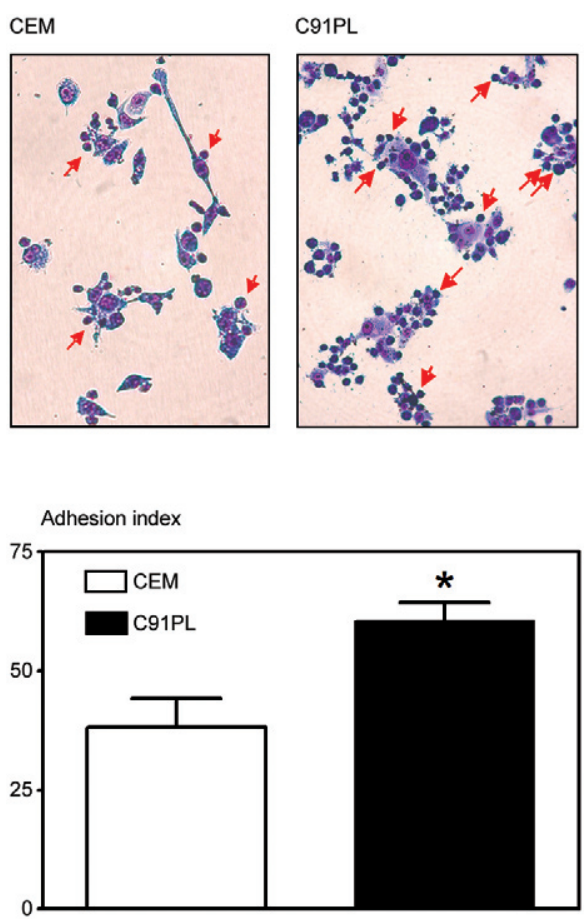

Fig. 1: comparative adhesion of non-infected and human T-lymphotropic virus type-1 (HTLV-1) infected T cell lines onto growing human thymic epithelial cells (TECs). HTLV-1 infected (C91PL) or noninfected (CEM) T lines were co-cultured with TECs for $2 \mathrm{~h}$. Upper panels depict co-cultures of human TEC with each T cell line. Arrows indicate adhered lymphocytes. Quantitation of this adhesion, showed in the bottom panel, reveals a significantly higher adhesion degree of HTLV-1 infected vs. non-infected T cells. Values correspond to mean \pm standard error of means of three independent experiments for each cell line. Asterisk means $p<0.05$. Original magnification $=200 \mathrm{X}$. 

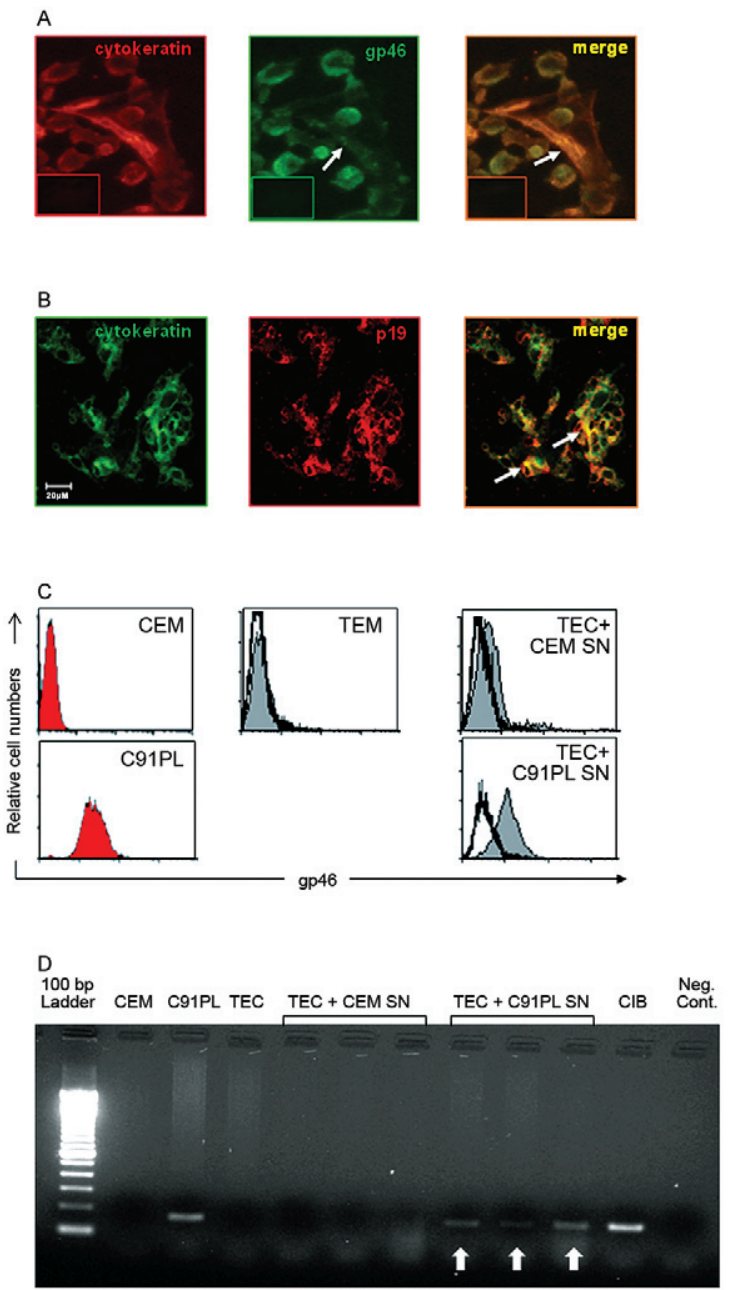

Fig. 2: evidence for human T-lymphotropic virus type-1 (HTLV-1) transfer from infected lymphocytes to human thymic epithelial cells (TECs). Panels A and B show the presence of the viral proteins gp46 (A) and p19 (B) in TECs (labeled for cytokeratins), as ascertained by double-labelling immunofluorescence after being co-cultured with HTLV-1 $1^{+}$lymphocytes for $24 \mathrm{~h}$. The arrows indicate the brightest areas of co-localization seen in the merged images. The cytofluorometric profiles seen in panel $\mathrm{C}$ show that TEC exhibit the gp46 on their surface, after being incubated for $1 \mathrm{~h}$, with supernatants derived from $\mathrm{HTLV}-1^{+}$infected (C91PL SN) or from non-infected (CEM SN) lymphocytes. Negative and positive controls for gp46 labelling are depicted in the histograms from CEM and C91PL cells, respectively. Also, TEC alone did not show any gp46 labelling. In all TEC profiles, empty histograms correspond to unrelated Ig-matched antibody, whereas the gp46 immunolabelling is shown in the gray curves. Panel D shows reverse transcription-polymerase chain reaction (PCR) detection of the HTLV-1 gene tax integrated into the genomic DNA of human thymic epithelial cells cultured in the presence of HTLV-1 infected T cell-derived supernatant. Non-infected CEM and HTLV-1 infected C91PL T cell lines were cultured for $72 \mathrm{~h}$. Their supernatants were harvested, filtered and put together with growing TEC for $90 \mathrm{~min}$. TEC genomic DNA was extracted and analyzed by PCR for detection of the HTLV-1 tax gene. TEC cultured in the presence of infected cell-derived supernatants presented the specific 190 bp labelling for the tax gene integrated in the genome indicated by the arrows. In addition to negative control for the PCR technique (Neg. Cont.), CEM and TEC DNA extracts did not show any labelling for the tax gene, whereas this gene were easily detected in extracts from two HTLV-1 $1^{+}$lymphocyte lines, C91PL and CIB. Bar $(\mathrm{A}, \mathrm{B})=20 \mu \mathrm{m}$.
In conclusion, we showed herein that the human thymic epithelium can be infected in vitro by HTLV-1, not only via cell-cell contact, but also via exposure to viruscontaining medium.

Given that activated $\mathrm{T}$ lymphocytes and dendritic cells recirculate from the periphery to the thymus (Tian et al. 2007, Li et al. 2009) and that HTLV-1 can be transmitted in a cell-free manner, as has been reported for dendritic cells (Jones et al. 2008), it is conceivable that $\mathrm{T}$ lymphocytes and dendritic cells, once infected by HTLV-1, carry the virus into the thymus and infect microenvironmental cells, such as TECs. Thus, we hypothesize that the human thymic epithelium is a putative reservoir for HTLV-1, opening up a research field related to the role of the thymus in the HTLV-1 infection cycle.

\section{REFERENCES}

Fernández E, Vicente A, Zapata A, Brera B, Lozano JJ, Martinez-AC, Toribio ML 1994. Establishment and characterization of cloned human thymic epithelial cell lines: analysis of adhesion molecule expression and cytokine production. Blood 83: 3245-3254.

Feuer G, Fraser J, Zack J, Lee F, Feuer R, Chen I 1996. Human Tcell leukemia virus infection of human hematopoietic progenitor cells: maintenance during differentiation in vitro and in vivo. J Virol 70: 4038-4444.

Foley GE, Lazarus H, Farber S, Uzman BG, Boone BA, McCarthy RE 1965. Continuous culture of human lymphoblasts from peripheral blood of a child with acute leukemia. Cancer 18: 522-529.

Ghez D, Lepelletier Y, Lambert S, Fourneau JM, Blot V, Janvier S, Arnulf B, van Endert PM, Heveker N, Pique C, Hermine O 2006. Neuropilin-1 is involved in human T-cell lymphotropic virus type 1 entry. $J$ Virol 80: 6844-6854.

Jones KS, Petrow-Sadowski C, Bertolette DC, Huang Y, Ruscetti FW 2005. Heparan sulfate proteoglycans mediate attachment and entry of human T-cell leukemia virus type 1 virions into CD4 T cells. J Virol 79: 12692-12702.

Jones KS, Petrow-Sadowsky C, Huang YK, Bertolette DC, Ruscetti FW 2008. Cell-free HTLV-I infects dendritic cells leading to transmission and transformation of $\mathrm{CD}^{+} \mathrm{T}$ cells. Nature Med 14: 429-436.

Lee TH, Chafets DM, Busch MP, Murphy EL 2004. Quantitation of HTLV-I and II proviral load using real-time quantitative PCR with SYBR Green chemistry. J Clin Virol 31: 275-282.

Lepelletier Y, Smaniotto S, Hadj-Slimane R, Villa-Verde DM, Nogueira AC, Dardenne M, Hermine O, Savino W 2007. Control of human thymocyte migration by Neuropilin-1/Semaphorin-3Amediated interactions. Proc Natl Acad Sci USA 104: 5545-5550.

Li J, Park J, Foss D, Goldschneider I 2009. Thymus-homing peripheral dendritic cells constitute two of the three major subsets of dendritic cells in the steady-state thymus. J Exp Med 206: 607-622.

Maguer-Satta V, Gazzolo L, Duc Dodon M 1995. Human immature thymocytes as target cells of the leukemogenic activity of human T-cell leukemia virus type I. Blood 86: 1444-1452.

Manel N, Kinet S, Battini JL, Kim FJ, Taylor N, Sitbon M 2003. The ubiquitous glucose transporter GLUT-1 is a receptor for HTLV. Cell 115: 449-459.

Mor-Vaknin N, Turgeman H, Torgeman A, Wolfson M, Huleihel M, Aboud M 1998. Rapid syncytium formation between human T-cell leukaemia virus type-I (HTLV-I)-infected T-cells and human nervous system cells: a possible implication for tropical spastic paraparesis/HTLV-I associated myelopathy. Cell Biol Int 22: 95-103. 
Murdoch AD, Liu B, Schwarting R, Tuan RS, Iozzo RV 1994. Widespread expression of perlecan proteoglycan in basement membranes and extracellular matrices of human tissues as detected by a novel monoclonal antibody against domain III and by in situ hybridization. J Histochem Cytochem 42: 239-249.

Nagai M, Brennan MB, Sakai JA, Mora CA, Jacobson S 2001. CD8 T cells are an in vivo reservoir for human T-cell lymphotropic virus type I. Blood 98: 1858-1861.

Osame M, Usuku K, Izumo S, Ijichi N, Amitani H, Igata A, Matsumoto M, Tara M 1986. HTLV-I associated myelopathy, a new clinical entity. Lancet 1: 1031-1032.

Popovic M, Lange-Wantzin G, Sarin PS, Mann D, Gallo RC 1983. Transformation of human umbilical cord blood T cells by human T-cell leukemia/lymphoma virus. Proc Natl Acad Sci USA 80: 5402-5406.

Proietti FA, Carneiro-Proietti AB, Catalan-Soares BC, Murphy EL 2005. Global epidemiology of HTLV-I infection and associated diseases. Oncogene 24: 6058-6068.
Ribeiro-Carvalho MM, Farias-de-Oliveira DA, Villa-Verde DMS, Savino W 2002. Triiodothyronine modulates extracellular matrix-mediated interactions between thymocytes and thymic microenvironmental cells. NeuroImmunoModulation 75: 139-150.

Setoyama M, Kerdel FA, Elgart G, Kanzaki T, Byrnes JJ 1998. Detection of HTLV-1 by polymerase chain reaction in situ hybridization in adult T-cell leukemia/lymphoma. Am J Pathol 152: 683-689.

Swainson L, Kinet S, Manel N, Battini JL, Sitbon M, Taylor N 2005. Glucose transporter 1 expression identifies a population of cycling $\mathrm{CD}^{+} \mathrm{CD}^{+}$human thymocytes with high CXCR4-induced chemotaxis. Proc Natl Acad Sci USA 102: 12867-12872.

Tian C, Bagley J, Iacomini J 2007. Homeostatic expansion permits T cells to re-enter the thymus and deliver antigen in a tolerogenic fashion. Am J Transpl 7: 1934-1941.

Uchiyama T, Yodoi J, Sagawa K, Takatsuki K, Uchino H 1977. Adult T-cell leukemia: clinical and hematologic features of 16 cases. Blood 50: 481-492. 